\title{
O USO DO BSC COMO FERRAMENTA GERENCIAL NO TRIBUNAL REGIONAL ELEITORAL DE ALAGOAS
}

\section{THE BSC USE AS MANAGEMENT TOOL IN THE ELECTORAL COURT OF THE STATE OF ALAGOAS}

\author{
Orlando Ramos do Nascimento Júnior ${ }^{1}$ \\ Alexandre Piones da Silva ${ }^{2}$ \\ Katia Jeane Alves Mota ${ }^{3}$
}

\section{RESUMO}

Devido ao aumento da exigência da sociedade por serviços de qualidade e por transparência na aplicação dos recursos públicos, tornou-se essencial para a administração pública buscar novos modelos para modernizar a sua gestão. As organizações de serviços públicos procuram hoje orientar a sua gestão para resultados e melhorias de desempenho. O sucesso da gestão depende de uma estratégia clara e de qualidade, que mobilize todos os envolvidos, alinhando as ações operacionais com essa estratégia para alcançar a melhoria contínua dos níveis de desempenho. Nesse contexto, o Balanced Scorecard tem sido a ferramenta mais utilizada nos últimos anos para comunicar, monitorar e avaliar a execução da estratégia. O processo de melhoria tem envolvido também os serviços públicos brasileiros, todavia, apesar de existirem algumas experiências, verifica-se um déficit generalizado de desempenho, que está explícito na forma como a opinião pública se refere à falta de eficiência, rapidez e qualidade dos serviços.

Palavras-chave: Balance Scorecard. Indicadores de desempenho. Gestão pública. Tribunal Regional Eleitoral de Alagoas.

\begin{abstract}
Due to increased demand from society for quality services and for transparency in the use of the public budget, became essential for the government to try on new models to overhal its management methods and at the same time to measure their performance in a systematic and structured way. This work attempted to contextualize the adoption of a management performance meter called Balanced Scorecard (BSC) by the Brazilian Electoral Court of the State of Alagoas (TRE/AL), as a public management tool for assessment of its organizational performance. The research was motivated by the importance of using performance indicators in Public Administration, looking for guidance from their management methods for results and performance improvements, aiming to contribute to make the state more agile and clear, focused on results which brings up value to society.
\end{abstract}

Keywords: Balanced Scorecard. Performance indicators. Public management. Tribunal Regional Eleitoral de Alagoas.

\footnotetext{
${ }^{1}$ Professor assistente da Universidade Estadual de Alagoas, doutorando em Administração pela Pontifícia Universidade Católica do Paraná. Rua Imaculada Conceição, 1155 - Bloco Acadêmico - Sala 103B - $1^{\circ}$ Andar - Prado Velho - Curitiba, PR - CEP: 80215901. E-mail: orlandoramosjr@gmail.com

${ }^{2}$ Especialista em Gestão - Centro Universitário - CESMAC - AL - Rua Cônego Machado, 918

Farol - Maceió, AL - CEP: 57051-160. E-mail: apiones@yahoo.com.br

${ }^{3}$ Especialista em Educação a Distância (EAD) - Faculdade de Tecnologia e Ciências - FTC-BA - Avenida Luís Viana Filho, 8812, Paralela - Salvador, BA - CEP: 41.741-590. E-mail: katiajeane1@ gmail.com
} 


\section{Introdução}

A mensuração do desempenho organizacional vem recebendo atenção crescente nos últimos dez anos. $\mathrm{O}$ assunto ganhou destaque em função da pressão crescente sofrida por grande parte das organizações por apresentarem resultados. Porém, esses resultados devem atender a expectativas de diversos públicos - ou stakeholders - que participam da organização e, de alguma forma, nela buscam atender alguma necessidade. Nesse sentido, as métricas tradicionais para avaliar o desempenho organizacional revelam sua fragilidade, pois se pautam quase exclusivamente em resultados financeiros, voltados principalmente aos interesses dos acionistas ou proprietários. Nessa lógica, outros stakeholders, como empregados ou comunidade, são preteridos.

Devido ao aumento da exigência da sociedade por serviços de qualidade e por transparência na aplicação dos recursos públicos, tornou-se essencial para a administração pública buscar novos modelos para modernizar a sua gestão. Assim, as organizações públicas procuram hoje orientar a sua gestão para resultados e melhorias de desempenho.

Nesse contexto, é preciso que a administração pública meça seu desempenho de maneira sistemática e estruturada. Para isso, faz-se necessário dotar as organizações públicas brasileiras de um modelo de avaliação do desempenho organizacional que contribua para tornar o Estado mais ágil, transparente e focado em resultados que agreguem valor à sociedade.

A importância da avaliação das instituições públicas vem se manifestando em diversos países e, em muitos casos, de forma vinculada à adoção de contratos de gestão ou formas assemelhadas de vincular ganhos de eficiência e eficácia à autonomização ou reautonomização dos aparelhos estatais. Em outros casos, vem se associando à adoção de formas mais flexíveis de gestão dos recursos humanos, cuja adequação varia da país para país conforme o perfil de seu corpo de funcionários e quadros de dirigentes (SANTOS; CARDOSO, 2001).

No Brasil, o Plano Diretor da Reforma do Aparelho do Estado (PDRAE), de 1995, lançou bases para a reforma gerencial. A estratégia definida fundamenta-se em três dimensões: a primeira, institucional-legal, que aborda os obstáculos de ordem legal 
para o alcance de maior eficiência do aparelho do Estado; a segunda, cultural, que trata da mudança da cultura burocrática para a gerencial; e a terceira aborda a gestão pública, incluindo os aspectos de modernização da estrutura organizacional e dos métodos de gestão. Entre as principais características dessa reforma, está sua orientação para o controle de resultados em vez do controle passo a passo das normas e dos procedimentos.

A literatura aponta o difícil e longo caminho trilhado por aqueles que se aventuram a construir sistemas de medição de desempenho, tanto em governos quanto em empresas privadas, destacando a importância de sua utilização para medir o sucesso de uma organização. O desafio levou Robert Kaplan e David Norton a desenvolver um modelo para medição denominado Balanced Scorecard (BSC), que abrange, além das medidas de desempenho financeiro, medidas não financeiras como relacionamento com clientes, qualidade, prazos de entrega, ciclo de produção, satisfação dos clientes, desempenho de processos e inovação. A estrutura do BSC possibilita uma visão equilibrada das áreas estratégicas da organização (financeira, relativa aos clientes, processos internos e aprendizado e crescimento) e incorpora medidas nessas áreas numa relação de causa e efeito para a melhoria do desempenho. Inúmeras organizações passaram a adotar esse modelo de medição (HERRERO, 2005).

\footnotetext{
A apresentação de indicadores de desempenho vem sendo exigida dos Tribunais Federais pelos órgãos de controle, como o Tribunal de Contas da União e o Conselho Nacional de Justiça. Ademais, os planejamentos estratégicos dos órgãos do Poder Judiciário deverão conter, pelo menos, um indicador de resultado para cada objetivo estratégico, segundo a Resolução $\mathrm{n}^{\circ}$ 70, de 18 de março de 2009, do Conselho Nacional de Justiça. (CONSELHO NACIONAL DE JUSTIÇA, 2009)
}

Desse modo, a pesquisa foi motivada pela importância da avaliação do desempenho dos órgãos públicos e pelo fato de o Tribunal Regional Eleitoral do Estado de Alagoas utilizar o Balanced Scorecard como metodologia a ser seguida para medição e avaliação de seu desempenho organizacional. Além disso, essa ferramenta de gestão estratégica é de ampla aplicação no setor privado e vem servindo de referencial às organizações públicas no desenvolvimento de seus próprios modelos de avaliação.

O objetivo geral deste estudo foi a análise do uso do BSC no Tribunal Regional Eleitoral de Alagoas (TRE/AL), a partir de pesquisa em livros, documentos e entrevistas e a utilização de indicadores para a avaliação da gestão pública. 
Para isso, estabeleceram-se os seguintes objetivos específicos:

$\checkmark$ discorrer sobre o Balanced Scorecard;

$\checkmark$ analisar os resultados da implantação do BSC no Tribunal Regional Eleitoral de Alagoas.

\section{Balanced Scorecard (BSC)}

Ao longo das últimas duas décadas, o setor público deparou-se com a necessidade de avaliar seus resultados, melhorar seu desempenho e demonstrar maior transparência, o que resultou na busca de melhorias em sua forma de operar. Várias estratégias de mudança têm sido adotadas, por diferentes instituições públicas, geralmente utilizando práticas gerenciais do setor privado. Assim, é reconhecida a importância da interligação entre as iniciativas de mudança e de aperfeiçoamento com as prioridades estratégicas, derivadas dos interesses dos stakeholders de uma organização, visto que, em organizações do setor público, há necessidade de conciliar os interesses de múltiplos stakeholders, tais como: governo, funcionários e cidadãos. Nesse sentido, a adoção da metodologia do Balanced Scorecard mostra-se bastante vantajosa, uma vez que essa técnica garante a explicitação da estratégia de governo, bem como o foco no uso dos recursos disponíveis (KAPLAN; NORTON, 2000).

O BSC difere das ferramentas tradicionais de avaliação de desempenho por ampliar o escopo dos indicadores, não se limitando apenas à consideração de resultados financeiros. O BSC enfatiza que os sistemas de informação devam disponibilizar indicadores financeiros e não financeiros para funcionários de todos os níveis na organização. Além disso, devido ao processo de implementação do BSC, em que há a discussão da missão e da estratégia dentro dos valores organizacionais, consegue-se mais efetivamente estabelecer a relação entre a medida obtida e a ação a ser tomada para a consecução de uma melhoria organizacional. Deixa, portanto, de ser uma ferramenta tática ou operacional, configurando-se em um importante subsídio para o planejamento estratégico.

Segundo Mansur (2008): 
Medir a performance do negócio é um desejo antigo dos administradores e é um desafio para a maioria das corporações. Atualmente existe no mercado um conjunto de regras financeiras para garantir a integridade da apuração do resultado financeiro das corporações. No entanto, esta caixa de ferramenta não mais está conseguindo medir corretamente a performance global da organização, devido à crescente complexidade do ambiente de negócios.

De acordo com o mesmo autor, as ferramentas da governança financeira não mais conseguem endereçar todas as perguntas dos stakeholders (acionistas, fornecedores, comunidade e sociedade) em relação aos resultados da organização. Considerando esse ambiente, o grande diferencial do Balanced Scorecard é que esse modelo incorpora as dimensões pseudofinanceiras (fatores não financeiros que afetam os resultados da empresa no segundo momento) ao framework de gestão financeira tradicional das corporações.

A nova realidade do ambiente de negócios demanda métodos de avaliação da performance mais abrangentes que levem em conta indicadores financeiros e não financeiros da performance do negócio. Nesse aspecto, o BSC mede o desempenho da organização de forma equilibrada sob o ponto de vista de quatro dimensões: financeira, cliente, processos internos, e aprendizado e crescimento, não se atendo, apenas, ao aspecto financeiro, como é comum nas outras ferramentas de gestão.

Algumas organizações têm utilizado o BSC para desenvolver sua estratégia de longo prazo clarificando e traduzindo visão e estratégia, comunicando e integrando objetivos estratégicos e indicadores, e planejando, estabelecendo metas e alinhando iniciativas estratégicas e aprimorando o controle e o aprendizado estratégico (KAPLAN; NORTON, 1997).

O Balanced Scorecard mede o desempenho organizacional contemplando quatro dimensões críticas - financeira, clientes, processos internos e aprendizagem e crescimento -, denominadas perspectivas, para a gestão estratégica da organização. Kaplan e Norton (1997) esclarecem que o modelo permite a utilização de um número maior de perspectivas, conforme as necessidades e contingências específicas de cada organização. No entanto, o importante é que as medidas de desempenho sejam equilibradas, abranjam todos os níveis da organização, da alta administração até o nível hierárquico mais baixo, de forma a alinhar todos os recursos à estratégia da organização. 
Segundo os mesmos autores, a estrutura do Balanced Scorecard está representada conforme Figura 1.

Figura 1 - Estrutura do Balanced Scorecard

Para alcançarmos nossa visão, como

Para sermos bem-sucedidos deveríamos ser vistos pelos nossos
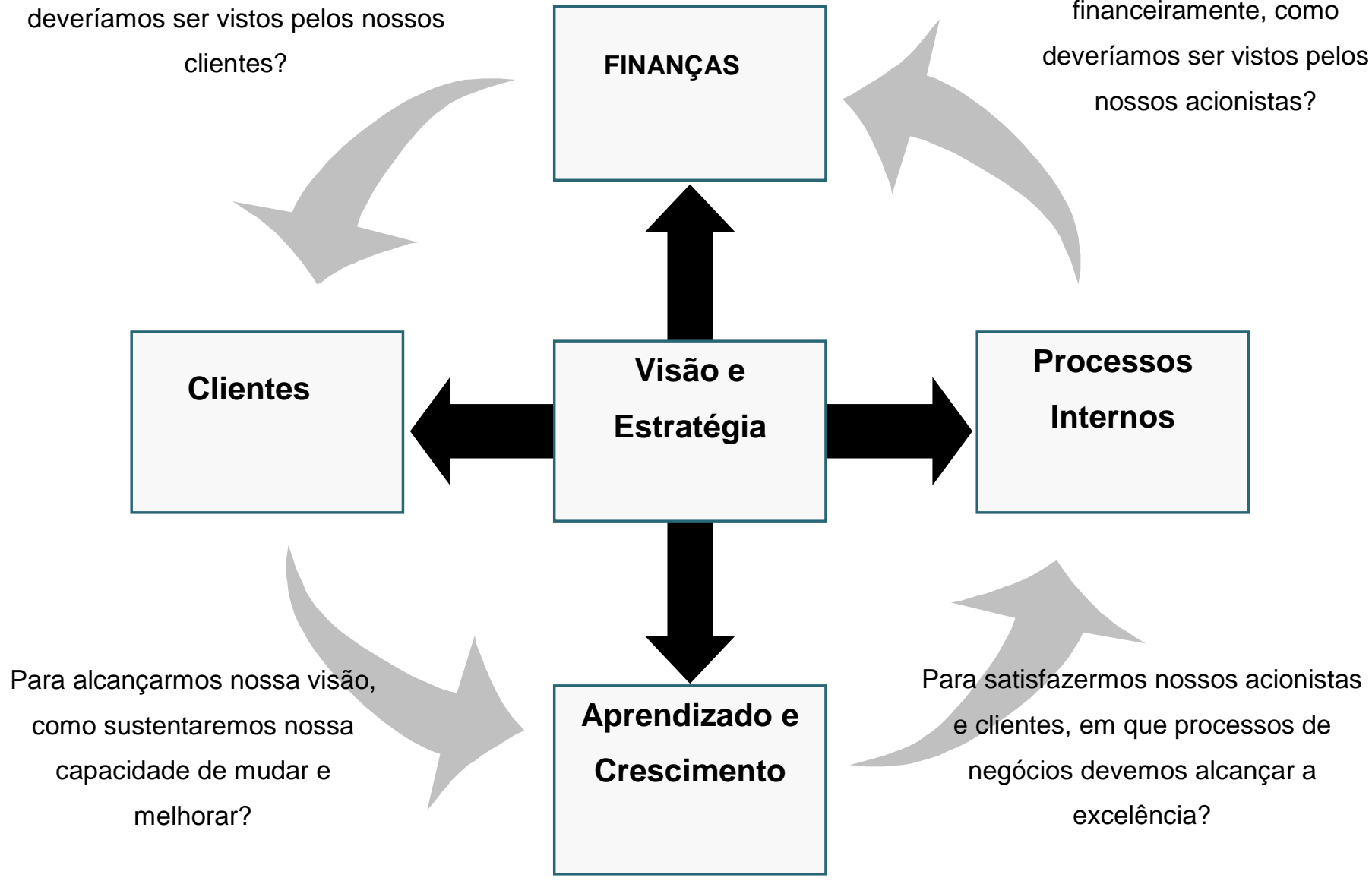
financeiramente, como

Fonte: Kaplan e Norton (1997).

A perspectiva financeira reflete os resultados do desempenho das demais perspectivas. As medidas são valiosas para sintetizar as consequências econômicas imediatas de ações já realizadas e indicam se a estratégia da organização está contribuindo para a melhoria dos resultados. Os objetivos financeiros servem de foco para os objetivos e medidas das outras perspectivas do scorecard. Segundo Kaplan e Norton (1997), "os objetivos e medidas financeiros precisam desempenhar um papel duplo: definir o desempenho financeiro esperado da estratégia e servir de meta principal para os objetivos e medidas de todas as outras perspectivas do scorecard".

Na perspectiva dos clientes do BSC, as empresas identificam os segmentos de clientes e mercado nos quais elas desejam competir. Esses segmentos representam as 
fontes que irão produzir o componente de receita dos objetivos financeiros da empresa. Essa perspectiva permite que as organizações alinhem suas medidas essenciais de resultados relacionados aos clientes - satisfação, fidelidade, retenção, captação e lucratividade - com segmentos específicos de clientes e mercado. As propostas de valor são os vetores, os indicadores de tendências, para as medidas de resultados na dimensão dos clientes.

$\mathrm{Na}$ perspectiva dos processos internos, os responsáveis pela gestão das organizações identificam os processos mais críticos para a realização dos objetivos dos clientes e financeiros. Para cada processo, devem ser desenvolvidas medidas que monitorem o desempenho, por exemplo, quanto à qualidade - taxa de defeito, desperdícios, retrabalho, devoluções; quanto ao tempo - resposta à solicitação, produção e entrega; quanto aos custos - custos dos processos; e quanto à inovação segmento de mercado a serem atendidos no futuro e vendas sobre produtos novos (KAPLAN; NORTON, 1997).

A quarta e última perspectiva do BSC desenvolve objetivos e medidas para orientar o aprendizado e o crescimento organizacional. Os objetivos estabelecidos nas perspectivas financeira, do cliente e dos processos internos revelam onde a organização deve destacar-se para obter um desempenho excepcional, enquanto os objetivos da perspectiva de aprendizado e crescimento oferecem a infraestrutura para o alcance dos objetivos das outras três perspectivas. Os vetores de aprendizado e crescimento provêm basicamente de três fontes: funcionários, sistemas e alinhamento organizacional (KAPLAN; NORTON, 1997).

Segundo Kaplan e Norton (1996 apud FERNANDES, 2009, p. 24):

Além da proposição das quatro perspectivas para monitoramento e controle, Kaplan e Norton sugerem a existência de relações de causalidade entre as dimensões. Os indicadores financeiros são atingidos à medida que a empresa atende e satisfaz seus clientes. Isso ocorre se os processos internos estiverem alinhados para alcançar a excelência; por fim, a excelência nos processos internos é consequência de pessoas motivadas e competentes, além de sistemas que respondam adequadamente às necessidades organizacionais. Essa ordem de causalidade é expressa nos chamados mapas causais. Todavia, vale destacar que cada organização deverá desenvolver seu mapa específico, segundo as dimensões que julgar mais relevantes. 
Os principais motivos que levam uma empresa a adotar o Balanced Scorecard como ferramenta de gestão é que os executivos desejam a melhoria do processo de gestão e da tomada de decisão e buscam maior alinhamento interno das principais áreas de negócios. Ademais, os administradores querem reduzir o vácuo existente entre a formulação da estratégia e o processo de implementação, pois o Balanced Scorecard, ao possibilitar a tradução da estratégia em termos operacionais, facilita esse processo. (HERRERO, 2005).

Segundo exposto por Herrero (2005, p. 25):

$\mathrm{Na}$ atual sociedade do conhecimento, marcada por globalização, desregulamentação, Internet, desintermediação, convergência entre os negócios e networking entre pessoas e empresas, medir apenas a saúde financeira de uma empresa não é mais suficiente. Agora, é preciso medir a saúde estratégica das organizações a longo prazo.

Mas, para avaliar se a posição competitiva de uma empresa está se fortalecendo ou, ao contrário, está se enfraquecendo, é preciso, antes, responder a algumas questões:

a. Dadas a missão e a visão de uma empresa, qual é a sua estratégia competitiva?

b. Tomando como referência essa estratégia, que indicadores de desempenho são os mais importantes?

c. Como esses indicadores quantitativos e qualitativos se relacionam entre si?

d. Que indicadores efetivamente demonstram o sucesso do negócio em gerar valor a longo prazo?

O Balanced Scorecard procura responder a essas perguntas. O BSC possibilita aos empresários e executivos identificarem em quais atividades críticas a empresa está gerando valor para os acionistas, clientes, colaboradores, fornecedores e para a comunidade.

Conforme o mesmo autor, o Balanced Scorecard é considerado um sistema balanceado de gestão porque promove equilíbrio entre as principais variáveis estratégicas:

$\checkmark$ entre os objetivos de curto e longo prazo;

$\checkmark$ entre o foco interno e o ambiente externo da organização;

$\checkmark$ entre medidas financeiras e medidas do capital intelectual;

$\checkmark$ entre os indicadores de ocorrência e os indicadores de tendências.

Por isso, o conceito de Balance Scorecard não é estático, mas sim dinâmico, e está sempre em evolução. Em uma perspectiva histórica, o Balance Scorecard, desde 
sua origem, em 1992, está numa contínua evolução, incorporando a aprendizagem e os novos conhecimentos decorrentes de sua implantação em centenas de empresas, em diferentes partes do mundo, e das pesquisas que Norton e Kaplan continuamente realizam em seu grupo de estudos denominado Balanced Scorecard Collaborative.

A evolução do conceito do BSC, segundo Herrero (2005), possui quatro fases: a primeira fase, o BSC como ferramenta de mensuração, é caracterizada pela pesquisa Medindo a Performance nas Organizações do Futuro (1990), liderada por Kaplan e Norton, com o objetivo de desenvolver um novo projeto de medição do desempenho. Os líderes das empresas participantes do projeto acreditavam que as medidas financeiras tradicionais de avaliação de desempenho estavam prejudicando a capacidade das empresas de criar valor econômico para o futuro.

A segunda fase, o BSC como ferramenta de implantação da estratégia, é caracterizada pela principal lição aprendida pelas empresas que adotaram o Balance Scorecard, que agora é utilizado como uma eficiente ferramenta para implantação da estratégia, e não apenas como um instrumento de mensuração da performance.

A terceira fase, o BSC como sistema de gestão estratégica, caracteriza-se pelo novo aprendizado das empresas que haviam implantado com sucesso o Balanced Scorecard. Agora o BSC permitia o alinhamento dos recursos organizacionais, como equipes, unidades de negócios, recrutamento e treinamento de empregados etc. e criava o foco necessário para a implementação da estratégia. As empresas que pretendessem se tornar uma organização orientada para a estratégia deviam seguir quatro princípios gerenciais: traduzir a estratégia em termos operacionais, alinhar a organização à estratégia, transformar a estratégia em processo contínuo e mobilizar a mudança por meio da liderança executiva.

A quarta fase, o BSC como modelo de gestão estratégica integrada, é caracterizada pelo aprendizado de dois novos conceitos: os objetivos estratégicos deveriam interligar-se em relações de causa e efeito à criação de mapas estratégicos que possibilitavam descrever e comunicar a estratégia para os participantes da organização.

Ademais, Kaplan e Norton (1997), a partir das quatro perspectivas, procuram incorporar, no processo de BSC, todos os avanços em gestão de negócios num sistema 
de gestão integrada. Os autores também enfatizam a gestão do conhecimento com o aprofundamento da metodologia da perspectiva de aprendizagem e renovação.

O setor privado tem reagido com maior rapidez que o setor público, adaptandose melhor ao cenário de mudanças e incertezas, modificando suas estratégias de atuação, aumentando sua eficiência e reduzindo seus custos de produção.

A Administração Pública pode e deve se inspirar no modelo de gestão privada, mas não pode perder a perspectiva de que, enquanto o setor privado visa à maximização do lucro, o setor público tem como objetivo cumprir a sua função social. Por isso, não se pode simplesmente aplicar diretamente os princípios da administração de empresas na gestão pública. O importante é fazer as apropriações e adaptações necessárias no sentido de dotar a Administração Pública de um modelo que efetivamente ajude a cumprir suas finalidades.

Como bem enfatizado por Herrero (2005), durante o período de implementação de um projeto de BSC, é recomendável um programa de educação continuada. Um simples treinamento, de poucas horas, não garante a aprendizagem. Ela só ocorre quando você recebe a informação, age e reflete sobre as experiências. As pessoas percebem melhor por meio de experiências e de suas reais necessidades.

Segundo o mesmo autor, o Balanced Scorecard é um processo de mudança organizacional a partir da estratégia na qual todos os colaboradores da organização devem estar envolvidos e comprometidos com o projeto, não apenas a alta administração. Assim, todos os funcionários devem entender e se alinhar em torno da estratégia, caso contrário, o projeto poderá ser comprometido. Além disso, toda a organização precisa participar da criação da estratégia, que não deve ser considerada uma área exclusiva da alta administração, mas sim uma atividade pluralista e participativa, em que as discussões devem abranger os diferentes setores da instituição, para possibilitar uma combinação inovadora de conhecimentos.

Ao longo das últimas duas décadas, o setor público deparou-se com a necessidade de avaliar seus resultados, melhorar seu desempenho e demonstrar maior transparência, o que resultou na busca de melhorias em sua forma de operar. Várias estratégias de mudança têm sido adotadas, por diferentes instituições públicas, geralmente utilizando práticas gerenciais do setor privado. 
Assim, é reconhecida a importância da interligação entre as iniciativas de mudança e de aperfeiçoamento com as prioridades estratégicas, derivadas dos interesses dos stakeholders de uma organização, visto que, em organizações do setor público, há necessidade de conciliar os interesses de múltiplos stakeholders, tais como: governo, funcionários e cidadãos. Nesse sentido, a adoção da metodologia do Balanced Scorecard mostra-se bastante vantajosa, uma vez que essa técnica garante a explicitação da estratégia de governo, bem como o foco do uso dos recursos disponíveis (KAPLAN; NORTON, 2000).

A apresentação de indicadores de desempenho vem sendo exigida nos Tribunais Federais pelos órgãos de controle, como o Tribunal de Contas da União e o Conselho Nacional de Justiça. Ademais, os planejamentos estratégicos dos órgãos do Poder Judiciário deverão conter, pelo menos, um indicador de resultado para cada objetivo estratégico, segundo a Resolução ${ }^{\circ}$ 70, de 18 de março de 2009, do Conselho Nacional de Justiça (CONSELHO NACIONAL DE JUSTIÇA, 2009).

O Tribunal Regional Eleitoral de Alagoas vem demonstrando interesse em orientar sua gestão para resultados e melhorias de desempenho, tornando os procedimentos mais céleres e principalmente mais efetivos. Contudo, verificou-se que a instituição pesquisada carece de melhor organização para o desempenho de suas atividades, com fins de evitar o retrabalho e racionalizar seus custos operacionais.

Ademais, percebeu-se que ainda há muita resistência por parte de alguns gestores quanto à utilização de ferramentas de avaliação de desempenho em organizações públicas.

A literatura sobre a difusão das práticas entre as organizações é caracterizada por um conjunto de explicações sobre os processos de adoção. Com suas origens na literatura econômica e baseia-se o modelo do ator racional. Essa abordagem concebe adotantes como atores racionais que fazem escolhas eficientes (FISS et al., 2012; KENNEDY e FISS, 2009; ROGERS, 1995). 


\section{Metodologia}

Esta pesquisa adotou a taxionomia apresentada por Vergara (2005), que apresenta dois critérios básicos: quanto aos fins e quanto aos meios. Quanto aos fins, a pesquisa é aplicada e exploratória. Aplicada, porque tem como finalidade a resolução de problemas concretos ao contribuir para o debate acerca da necessidade de utilizar a ferramenta de gestão estratégica conhecida como Balanced Scorecard à realidade de uma gestão pública focada em resultados e orientada ao cidadão. A pesquisa é exploratória, pois é realizada numa área na qual não há muito conhecimento sobre o tema.

Quanto aos meios de investigação, a pesquisa é bibliográfica e participante. A pesquisa é bibliográfica por ser desenvolvida com base em material acessível ao público em geral e publicado em livros, internet, revistas e artigos sobre gestão pública e Balanced Scorecard. E é participante, pois foram realizadas entrevistas com aplicação de questionários com perguntas abertas, para conhecer a experiência de implantação do BSC no Tribunal Regional Eleitoral de Alagoas.

$\mathrm{Na}$ instituição pesquisada foram realizadas entrevistas com oito gestores das seguintes unidades: direção-geral, Secretaria de Tecnologia da Informação, Secretaria judiciária, Secretaria de Administração, Coordenadoria de Controle Interno, Coordenadoria de Pessoal, Corregedoria e um representante dos Cartórios Eleitorais.

A coleta dos dados foi realizada por meio de um questionário de sete perguntas abertas, respondido pessoalmente pelos entrevistados. Dessas questões, seis são perguntas comuns a todos os entrevistados, e uma é dirigida a cada gestor de sua respectiva unidade. Todas as perguntas foram referentes à ferramenta de gestão Balanced Scorecard, com base nos documentos "Plano de Gestão 2009-2010" e "Planejamento Estratégico 2010-2014" da instituição (TRIBUNAL REGIONAL ELEITORAL DE ALAGOAS, 2009; 2010).

Procurou-se ouvir o relato de cada entrevistado e questioná-los para mais bem conhecer a experiência da implantação do BSC nessa organização. 


\section{Análise dos resultados}

Em primeiro lugar, foi perguntado aos entrevistados sobre os motivos que levaram o TRE/AL a adotar a ferramenta de gestão Balanced Scorecard para medir o seu desempenho organizacional. Segundo todos os entrevistados, a principal motivação foi a exigência do Tribunal de Contas da União e do Conselho Nacional de Justiça, que passaram a cobrar dos tribunais federais a instituição de indicadores de resultados, metas, projetos e ações de âmbito nacional, comuns a todos os tribunais. Dois gestores responderam que, além da exigência dos órgãos de controle, optou-se pela utilização do BSC em grande parte por se tratar de uma ferramenta mais adequada para a medição da performance da instituição.

Ademais, o Tribunal de Contas da União utiliza-se da metodologia BSC para exame e julgamento das tomadas e prestação de contas dos gestores públicos, através de indicadores de controle da conformidade e do desempenho da gestão, bem como o Tribunal Superior Eleitoral, que também faz uso do BSC para dar suporte ao seu processo de gestão estratégica (TRIBUNAL SUPERIOR ELEITORAL, 2009).

Segundo Mansur (2008), existem vários benefícios para uma organização utilizar o BSC como ferramenta de gestão, dentre os quais se destacam: o alinhamento das ações com os objetivos da empresa, visão clara da empresa, integração da estratégia de gerenciamento para toda a organização, habilitação de uma poderosa ferramenta para o gerenciamento e priorização de iniciativas, facilitação do gerenciamento da estratégia da organização, além da criação de uma estrutura comum para várias iniciativas, além de facilitar a comunicação com acionistas, fornecedores e clientes.

A seguir, foi perguntado se houve alguma adaptação ao modelo do BSC, por se tratar de setor público. Três entrevistados afirmaram que, como se trata de órgão público, a perspectiva cliente foi posta em primeiro plano, uma vez que a prioridade da instituição é atender às necessidades da sociedade. No entanto, após verificar o mapa estratégico da instituição, constatou-se que a perspectiva "cliente" não foi posta em destaque. Os outros entrevistados não souberam informar se houve alguma adaptação ao modelo. 
Nesse sentido, vale destacar que Kaplan e Norton (2000) afirmam que o Balanced Scorecard pode ser facilmente adaptado para organizações públicas e instituições sem fins lucrativos, possibilitando a essas organizações manter seus gastos dentro dos limites orçamentários e atender a seus clientes e partes interessadas.

No entanto, não é possível simplesmente aplicar diretamente os princípios da administração de empresas na gestão pública. O importante é fazer as apropriações e adaptações necessárias no sentido de dotar a Administração Pública de um modelo que efetivamente ajude a cumprir sua função social.

Em seguida, foi perguntado se o tribunal utilizava alguma ferramenta de medida de desempenho antes de adotar o BSC para esse fim. De acordo com todos os gestores do órgão, não havia qualquer outro tipo de ferramenta de gestão anterior à adoção da ferramenta BSC para a avaliação do desempenho organizacional. Segundo um gestor, havia apenas os relatórios de gestão, que traziam uma avaliação concentrada em indicadores financeiros e orçamentários, em detrimento dos demais indicadores.

Nesse diapasão, Drucker (1995 apud FERNANDES, 2009) enfatiza que só se pode gerenciar aquilo que se pode medir. $\mathrm{O}$ objetivo primário de medir a performance organizacional é permitir que os gestores entendam onde a organização está e o que pode ser feito para aperfeiçoar o desempenho. Além disso, o mesmo autor avalia os sistemas tradicionais de gestão como pobres em fornecer informações para tomada de decisões, e sugere outras dimensões a serem monitoradas para uma visão mais abrangente do desempenho.

Perguntados se houve algum programa de treinamento voltado aos servidores da instituição para que conhecessem a ferramenta Balanced Scorecard e se houve o envolvimento de todos os funcionários, a maioria dos gestores informou não ter havido qualquer tipo de treinamento para divulgar a ferramenta que estava sendo implantada, bem como não houve o envolvimento de todos os servidores da organização. Segundo três entrevistados, apenas alguns gestores participaram de um curso em Brasília, promovido pela consultoria Symnetics Educação para conhecimento da metodologia BSC. 
Indagados sobre as principais dificuldades encontradas na implantação do projeto de BSC e quais os benefícios oriundos de sua implantação, verificou-se que a maioria dos entrevistados não soube informar acerca das dificuldades enfrentadas na fase de implantação da ferramenta. Três gestores disseram que as principais dificuldades enfrentadas foram: desconhecimento da ferramenta por parte da maioria dos gestores envolvidos no projeto, resistência e desconforto por parte de alguns gestores em adotar mecanismos de avaliação e controle de resultados e falta de integração das áreas envolvidas. Em relação aos benefícios, os gestores entrevistados responderam que ainda não sentiram na prática os reais benefícios oriundos da implantação da ferramenta, pois ainda é cedo para fazer esse tipo de avaliação, uma vez que o BSC ainda não foi de fato implementado. Apenas um gestor informou que após a implantação da nova metodologia houve maior integração entre as unidades do tribunal, bem como um maior interesse por parte dos servidores em conhecer essa nova abordagem em gestão estratégica.

Em sequência, perguntou-se se a organização havia contratado alguma empresa de consultoria especializa para elaborar o projeto de BSC, e quanto tempo foi gasto para a sua implantação. Após ouvir o relato dos entrevistados, verificou-se que muitos dos gestores não souberam informar se o tribunal havia contratado alguma empresa de consultoria especializada em BSC ou se elaborou o projeto através de sua equipe de colaboradores, bem como não tinham conhecimento acerca de quanto tempo foi gasto na implantação do projeto.

Quatro gestores dentre os entrevistados informaram que no ano de 2009 o tribunal recebeu orientação da Fundação Getúlio Vargas, contratada pelo Conselho Nacional de Justiça, para auxiliar na formulação de seus indicadores de desempenho.

Finalmente, indagados se havia algum tipo de monitoramento para observar se, de fato, os objetivos almejados pela instituição estavam se convertendo em realidade, bem como se essas unidades faziam a medição de seus indicadores, verificouse que não há, de forma integrada, nenhum mecanismo de monitoramento para aferir se os objetivos almejados pela organização estão sendo postos em prática. Além disso, a maioria dos entrevistados não soube apontar como é feita a medição dos indicadores definidos para suas respectivas unidades. Apenas três gestores conheciam esses 
indicadores, mesmo que no planejamento estratégico da instituição conste referência a eles.

Os indicadores devem ser simples e de fácil leitura. As colaboradoras da instituição devem entender o indicador. Além disso, as medidas têm de comunicar o comportamento desejado das pessoas em relação à estratégia. Os indicadores que são monitorados geram mudança de comportamento. As pessoas respondem ao que é comunicado, e não ao que é esperado, ou seja, não conseguem adivinhar o que é esperado delas, se não for bem comunicado (HERRERO, 2005).

Segundo Fernandes (2009), o papel do sistema de mensuração de performance é monitorar se os propósitos desejados pela organização, aqueles que impulsionaram as ações, estão de fato acontecendo. Ademais, um bom sistema de mensuração de desempenho pode proporcionar sintonia fina para o gestor acompanhar o grau em que atinge seus objetivos.

Indicadores claros de avaliação aumentam a transparência da gestão e facilitam o diálogo entre a administração pública e os usuários dos serviços públicos, e são importantes ferramentas gerenciais de gestão pública e um instrumento fundamental para a fiscalização por parte da sociedade.

\section{REFERÊNCIAS}

CONSELHO NACIONAL DE JUSTIÇA. Resolução no 70 de 18 de março de 2009. Disponível em: <http://www.cnj.jus.br/index.php?option=com_content\&view=article\&i d=7024:resolucao-no-70-de-18-de-marco de2009\&catid=57>. Acesso em: 14 mar. 2013.

FERNANDES, B. H. R. Competências e desempenho organizacional: o que há além do balance scorecard. São Paulo: Saraiva, 2009. 
FISS, P. C.; KENNEDY, M. T.; DAVIS, G. F. How golden parachutes unfolded: Diffusion and variation of a controversial practice. Organization Science, v. 23, n. 4, p. 1077-1099, 2012.

FISS, P. C.; ZAJAC, E. J. The symbolic management of strategic change: Sensegiving via framing and decoupling. Academy of Management Journal, v. 49, n. 6, p. 11731193, 2006.

HERRERO, E. Balanced scorecard e a gestão estratégica: uma abordagem prática. 10. ed. Rio de Janeiro: Elsevier, 2005.

KAPLAN, R. S.; NORTON, D. P. A estratégia em ação - Balanced Scorecard. 7. ed. Rio de Janeiro: Campus, 1997.

Organização orientada para a estratégia: como as empresas que adotam o balanced scorecard prosperam no novo ambiente de negócios. 4. ed. Rio de Janeiro: Campus, 2000.

\section{The execution premium: linking strategy to}

operations for competitive advantage. Boston, MA: Harvard Business School Press, 2008.

MANSUR, R. Balanced scorecard: Estudo de casos brasileiros. Rio de Janeiro: Editora Ciência Moderna Ltda., 2008.

SANTOS, L. A.; CARDOSO, R. L. S. Avaliação de desempenho da ação governamental no Brasil: problemas e perspectivas. XV Concurso de Ensayos Del Clad - Control y Evaluación Del Desempeño Gubernamental. Caracas - 2001. Disponível em: <http://unpan1.un.org/intadoc/groups/public/documents/clad/clad0041201.pdf >. Acesso em: 10 fev. 2013.

TRIBUNAL SUPERIOR ELEITORAL. Plano de gestão 2009-2010. Disponível em: <http://intranet.tse.gov.br/institucional/planoGestao/planoGestao2009-2010.pdf>. Acesso em: 4 mar. 2013. 
VERGARA, S. C. Projetos e relatórios de pesquisa em administração. São Paulo: Atlas, 2005.

Recebimento dos originais: $18 / 02 / 2014$

Aceitação para publicação: 15/06/2014 